\title{
LAJU EKSPLOITASI IKAN TENGGIRI DAN TONGKOL DI KAWASAN KONSERVASI TAMAN NASIONAL KARIMUNJAWA
}

\author{
Ernik Yuliana \\ Nurhasanah \\ FMIPA Universitas Terbuka \\ e-mail: ernik@ecampus.ut.ac.id
}

\begin{abstract}
Karimunjawa National Park (KNP) is a marine protected area established to preserve ecosystems and natural resources. Scomberomorus commerson (tenggiri) and Euthynnus affinis (tongkol) arethe two species of pelagic fish which are the main catches for artisanal fishery in KNP. This study was aimed to analyze the exploitation rate of S. commerson and E. affinis. Field survey was conducted in KNP District of Jepara, Central Java, in JuneSeptember 2016. The exploitation rate is measured by analytical method based on fish's growth and mortality, through measuring the length of the fish for three months. Totally, as many as 314 individuals of $S$. Commersonand 499 individuals of E. Affinis were measured. The data were analyzed using Fish Stock Assessment Tools (FISAT II) statistical program. The results indicated that $S$. Commerson have a body-size trend that tends to increase, with the rate of exploitation $(E)$ was 0,29 (under-exploited), which means there is anopportunity to increase it's utilization. At the other hand, the size of $E$. Affinis tends to decrease, with the rate of exploitation $(E)=0,5$. It means that the condition of utilization of $E$. Affinis was at alarming position. It is necessary to control the tongkol fishing by regulating fishing gear, in order to avoid overfishing situation.
\end{abstract}

Keywords: euthynnus affinis, exploitation rate, Karimunjawa, marine protected area, scomberomorus commerson

\begin{abstract}
ABSTRAK
Taman Nasional Karimunjawa (TNKJ) merupakan salah satu kawasan konservasi yang bertujuan melindungi kelestarian ekosistem dan sumber daya alam. Ikan tenggiri

(Scomberomorus commerson)dan tongkol (Euthynnus affinis) adalah ikan pelagis yang merupakan tangkapan utama di TNKJ. Tujuan studi ini adalah menganalisis laju eksploitasi ikan tenggiri dan tongkol. Penelitian dilakukan pada bulan Juni-September 2016.

Pengukuran laju eksploitasi menggunakan metode analitik didasarkan pada pertumbuhan dan mortalitas ikan, dengan mengukur panjang ikan hasil tangkapan selama tiga bulan. Jumlah ikan tenggiri yang diukur adalah 314 ekor, dan ikan tongkol adalah 499 ekor. Analisis data menggunakan program Fish Stock Assessment Tools (FISAT II). Hasil penelitian menunjukkan tren ukuran ikan tenggiri cenderung meningkat, dengan laju eksploitasi $(E)=0,29$ (under exploited), sehingga pemanfaatannya dapat ditingkatkan. Sementara ukuran ikan tongkol cenderung menurun, dengan laju eksploitasi $(E)=0,5$. Kondisi pemanfaatan ikan tongkol berada pada posisi mengkhawatirkan. Sehingga perlu dilakukan pengelolaan terhadap penangkapan ikan tongkol agar tidak mengarah ke penangkapan berlebih, dengan mengatur alat tangkap nelayan.
\end{abstract}


Kata kunci: kawasan konservasi perairan,Karimunjawa, tenggiri, tongkol, laju eksploitasi

Ikan tenggiri dan tongkol merupakan ikan pelagis yang merupakan hasil tangkapan utama di Perairan Karimunjawa (PPP Karimunjawa, 2014). Kedua ikan tersebut ditangkap oleh nelayan lokal dengan alat tangkap jaring dan pancing. Ikan pelagis merupakan elemen kunci dalam rantai makanan laut, termasuk bagian penting dari keseluruhan ekosistem yang sehat (Shephard, et al., 2014). Hasil analisis comparataive performance index (CPI) terhadap kelompok ikan pelagis besar, menunjukkan bahwa ikan tenggiri dan tongkol menempati prioritas utama di Karimunjawa (Irnawati, dkk., 2011).

Kepulauan Karimunjawa merupakan suatu kelompok pulau-pulau kecil yang berjumlah 27 pulau. Sebagian wilayah perairan Karimunjawa ditetapkan sebagai kawasan konservasi, meliputi 22 pulau dan lima pulau selebihnya berada di luar kawasan konservasi (BTNKJ, 2014). UU No.5 Tahun 1990 tentang Konservasi Sumber Daya Alam Hayati dan Ekosistemnya membagi kawasan konservasi menjadi beberapa jenis pengelolaan, salah satunya adalah taman nasional. Definisi taman nasional menurut undang-undang tersebut adalah kawasan pelestarian alam yang mempunyai ekosistem asli, dikelola dengan sistem zonasi yang dimanfaatkan untuk tujuan penelitian, ilmu pengetahuan, pendidikan, menunjang budidaya, pariwisata, dan rekreasi.

Karimunjawa ditetapkan sebagai taman nasional melalui SK Menhutbun No. 78/Kpts-II/1999 pada 22 Februari 1999. Pada tahun 2001, seluruh kawasan perairan di TNKJ ditetapkan sebagai Kawasan Pelestarian Alam Perairan melalui Keputusan Menteri Kehutanan No.74/Kpts-II/2001 (Campbell, et al. 2013). Wilayah yang dilindungi oleh TNKJ sebagian besar adalah perairan, dengan melindungi ekositem terumbu karang sebagai daerah spawning ground, nursery ground, dan feeding ground bagi ikan dan biota lainnya.

Aktivitas penangkapan di TNKJ harus diikuti dengan pemasyarakatan teknologi penangkapan ikan tepat guna dalam rangka pengembangan pemanfaatan sumber daya ikan (SDI) dan peningkatan keterampilan dan budaya masyarakat nelayan di kawasan Karimunjawa. Penerapan teknologi penangkapan tepat guna harus sejalan dengan upaya menjaga kelestarian dan keberlanjutan lingkungan (Irnawati, dkk., 2011). Namun, penangkapan ikan di dalam kawasan TNKJ yang dilakukan oleh nelayan skala kecil (< 5 gross tonnage/GT) sering kali menggunakan alat tangkap yang tidak ramah lingkungan, misalnya penggunaan pottasium, bom, dan jaring cantrang (Campbell, et al. 2013). Hal tersebut mengkhawatirkan terjadinya degradasi ekosistem terumbu karangdan SDI.Untuk menganalisis keberlanjutan SDI tenggiri dan tongkol di TNKJ perlu dilakukan studi tentang laju eksploitasi kedua ikan tersebut. Laju eksploitasi berguna untuk menganalisis keberlanjutan pengelolaan perikanan. Salah satu aspek berkelanjutan perikanan adalah memelihara keberlanjutan stok atau biomassa agar tidak melewati daya dukungnya (Charles, 2001).

Penelitian tentang laju eksploitasi ikan-ikan hasil tangkapan di Karimunjawa pernah dilakukan sebelumnya oleh Yuliana et al. (2016) yang memfokuskan pada laju eksploitasi empat jenis ikan karang. Hasil penelitian tersebut adalah ikan ekor kuning (Caesio cuning) memiliki laju eksploitasi 0,41; pisang-pisang (Caesio caerulaurea) 0,57; sunu macan (Plectropomus oligocanthus) 0,77; dan jenggot (Parupeneus barberinus) 0,26. Namun khusus untuk pengukuran laju eksploitasi ikan tenggiri dan tongkol di TNKJ belum pernah dilakukan dalam tahun-tahun terakhir ini, padahal data tersebut perlu diketahui,agar dapat menjadi dasar untuk pengelolaan ikan tenggiri dan ikan tongkol di lokasi tersebut. 
Tulisan ini bertujuan untuk mengukur laju eksploitasi ikan tenggiri dan tongkol, kemudian menganalisis langkah-langkah yang perlu diambil oleh pengelola TNKJ dan para pemangku kepentingan untuk menjaga keberlanjutan SDI tenggiri dan tongkol.

\section{METODE}

Penelitian dilakukan di TNKJ Kabupaten Jepara, Provinsi Jawa Tengah, pada JuniSeptember 2016. Pengumpulan data menggunakan metode survei dan observasi, mencakup data primer dan sekunder. Pengukuran laju eksploitasi menggunakan metode analitik dengan menganalisis pertumbuhan dan mortalitas ikan berdasarkan data panjang ikan. Pengukuran panjang ikan dilakukan terhadap ikan hasil tangkapan di tiga pengepul Desa Karimunjawa, selama tiga bulan (lima kali pengambilan contoh). Jumlah ikan tenggiri (Scomberomorus commerson) yang diukur panjangnya adalah 314 ekor, dan ikan tongkol (Euthynnus affinis) adalah 499 ekor, hasil tangkapan jaring insang dan pancing. Data sekunder diperoleh dari Pelabuhan Perikanan Pantai (PPP) Karimunjawa, berupa data hasil tangkapan harian, jenis alat tangkap, dan jumlah upaya tangkap tahun 2014.

Analisis data menggunakan program Fish Stock Assessment Tools (FISAT II), dengan mengukur pertumbuhan dan mortalitas ikan. Pertumbuhan ikan ( $K$ dan $\left.\mathrm{L}_{\infty}\right)$ dianalisis berdasarkan data frekuensi panjang dengan bantuan metode ELEFAN I. Koefisien pertumbuhan yang digunakan mengikuti model von Bertalanffy (Sparre \& Venema, 1999) yang dirumuskan sebagai:

$L_{t}=L_{\infty}\left[1-e^{\left(-K\left(t-t_{0}\right)\right)}\right]$

$\mathrm{L}_{t}$ adalah ukuran ikan pada umur $\mathrm{t}(\mathrm{cm}), \mathrm{L}_{\infty}$ adalah panjang asimptotik $(\mathrm{cm}), \mathrm{K}$ adalah koefisien pertumbuhan (per tahun), dan $t_{0}$ adalah umur hipotesis ikan pada panjang nol (per tahun).

Mortalitas alami (M) diduga dengan menggunakan rumus empiris Pauly (1984) di dalam

Sparre dan Venema (1999) sebagai berikut:

$M=\exp \left(-0,0152-0,279 \ln L_{\infty}+0,6543 \ln \mathrm{K}+0,463 \ln \mathrm{T}\right)$

$\mathrm{T}$ adalah suhu perairan, pada penelitian ini suhu yang digunakan adalah suhu perairan Karimunjawa $30^{\circ} \mathrm{C}$ (Yuliana, dkk., 2016). Mortalitas penangkapan (F) dapat ditentukan melalui hubungan:

$\mathrm{F}=\mathrm{Z}-\mathrm{M}$

Laju eksploitasi (E) diukur dengan membandingkan laju penangkapan $(F)$ dengan laju mortalitas total (Z) (Pauly, 1984):

$E=\frac{F}{F+M}=\frac{F}{Z}$

\section{HASIL DAN PEMBAHASAN}

\section{Kondisi Hasil Tangkapan di TNKJ}

Aktivitas penangkapan ikan di TNKJ dilakukan oleh nelayan lokal dengan alat tangkap tradisional yang sudah turun-temurun dilakukan di TNKJ. Untuk memelihara keberlanjutan ekosistem, Balai Taman Nasional Karimunjawa (BTNKJ) menyediakan zona tradisional perikanan untuk aktivitas penangkapan. Berdasarkan data PPP Karimunjawa (2014), sebagian besar hasil tangkapan di TNKJ adalah ikan pelagis, disusul oleh ikan karang, cumi, dan lainnya. Hasil penelitian ini memperlihatkan bahwa jenis ikan pelagis besar, tenggiri dan tongkol merupakan dua jenis yang mempunyai catch per unit effort (CPUE) terbesar (Tabel 1). Secara proporsional, hasil tangkapan ikan pelagis terbesar di 
TNKJ adalah tongkol $(44,48 \%)$, kemudian teri $(30,51 \%)$, tenggiri $(14,97 \%)$, dan badong $(5,06 \%)$ (Gambar 1).

Tabel 1. Hasil Tangkapan Ikan di TNKJ Tahun 2014 (PPP Karimunjawa, 2014).

\begin{tabular}{llrcc}
\hline Jenis ikan & Alat tangkap & Trip & $\begin{array}{c}\text { Jumlah } \\
\text { tangkapan }(\mathrm{kg})\end{array}$ & $\begin{array}{c}\text { CPUE } \\
(\mathrm{kg} / \text { trip) }\end{array}$ \\
\hline Tongkol & Pancing tonda & 3.380 & 81.800 & 24,20 \\
& Jaring insang & 515 & 17.400 & 33,76 \\
Tenggiri & Pancing ulur & 1.496 & 33.385 & 22,31 \\
Badong & Pancing ulur & 608 & 11.275 & 18,53 \\
Kakap merah & Pancing ulur & 610 & 13.500 & 22,13 \\
& Bubu & 715 & 14.570 & 20,36 \\
Ekor kuning & Panah & 3.145 & 94.700 & 30,11 \\
& Bubu & 119 & 2.950 & 24,73 \\
Betet/ijo & Panah & 538 & 15.300 & 28,41 \\
Kerapu & Bubu & 274 & 4.517 & 16,48 \\
& Pancing ulur & 158 & 2.600 & 16,41 \\
Cumi-cumi & Pancing ulur & 105 & 1.450 & 13,76 \\
Teri & Jaring angkat & 1.429 & 68.050 & 47,62 \\
Lainnya & Bubu & 291 & 6.870 & 23,53 \\
& Panah & 75 & 2.300 & 30,58 \\
& Pancing ulur & 121 & 1950 & 16,06 \\
\hline
\end{tabular}

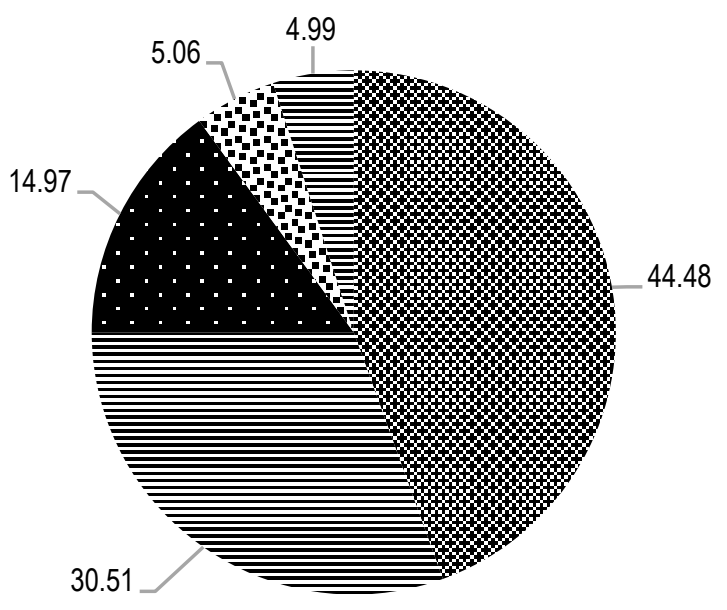

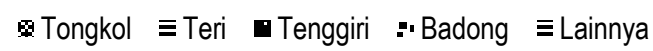

Gambar 1. Proporsi hasil tangkapan ikan pelagis di TNKJ (Sumber data: PPP Karimunjawa, 2014) 
Pada studi ini ikan pelagis yang menjadi objek penelitian adalah tenggiri dan tongkol yang ditangkap dengan pancing, karena kedua ikan tersebut mempunyai hasil tangkapan tertinggi dan pancing adalah alat tangkap yang banyak digunakan oleh nelayan. CPUE tenggiri dan tongkol berfluktuasi per bulan dalam tahun yang sama (Gambar 2). CPUE tertinggi untuk ikan tenggiri pada tahun 2014 adalah bulan November, sementara CPUE ikan tongkol tertinggi adalah pada bulan Juli.

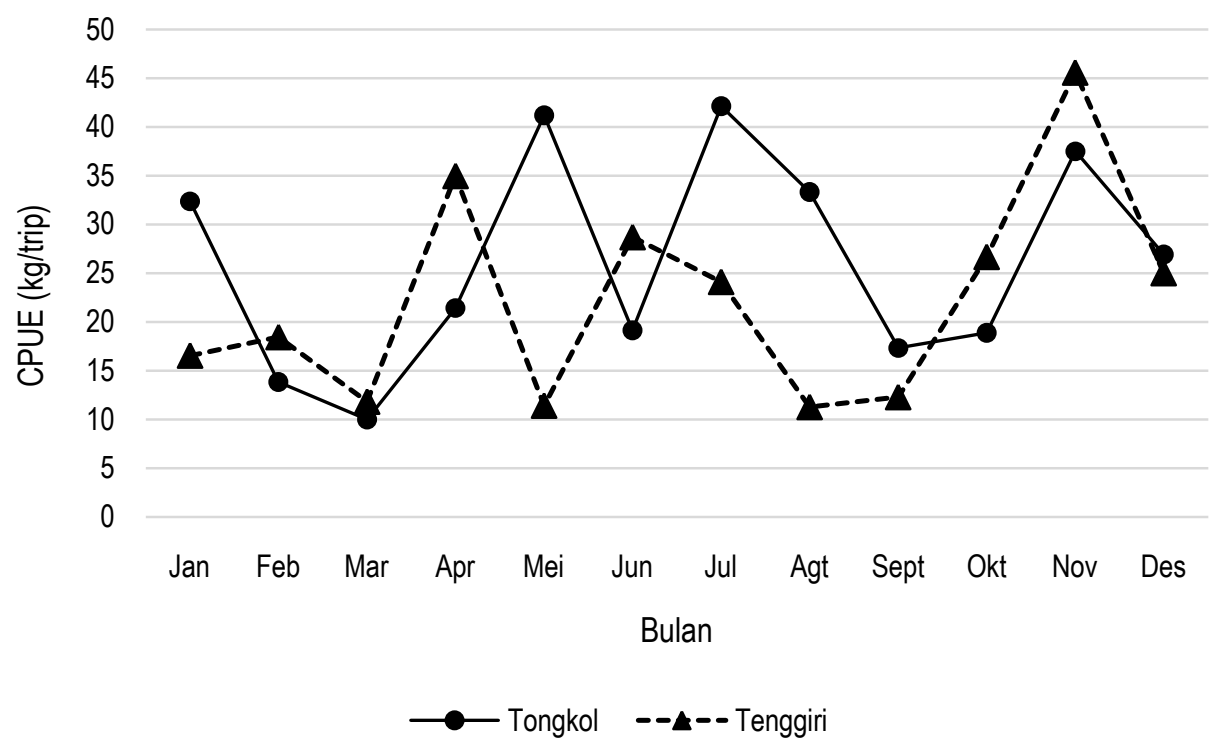

Gambar 2. Fluktuasi hasil tangkapan tenggiri dan tongkol yang ditangkap dengan pancing per bulan tahun 2014 (Sumber data: PPP Karimunjawa, 2014)

\section{Kelompok Ukuran Ikan}

Berdasarkan data panjang ikan, dilakukan pendugaan kelompok ukuran ikan menggunakan Metode Normsep (normal separation) pada program FISAT II, hasilnya disajikan pada Tabel 2.

Grafik tren ukuran ikan tenggiri dan tongkol pada waktu pengambilan contoh berturut-turut disajikan pada Gambar 3 dan 4.

Tabel 2. Kelompok Ukuran Ikan.

\begin{tabular}{|c|c|c|c|c|c|}
\hline \multirow[b]{2}{*}{ Sampling ke- } & \multirow{2}{*}{$\begin{array}{c}\text { Waktu } \\
\text { Pengambilan } \\
\text { contoh }\end{array}$} & \multicolumn{2}{|c|}{ Tenggiri } & \multicolumn{2}{|c|}{ Tongkol } \\
\hline & & $\begin{array}{c}\text { Panjang lkan } \\
(\mathrm{cm})\end{array}$ & $\begin{array}{c}\text { Simpangan } \\
\text { Baku }\end{array}$ & $\begin{array}{l}\text { Panjang lkan } \\
(\mathrm{cm})\end{array}$ & $\begin{array}{c}\text { Simpangan } \\
\text { Baku }\end{array}$ \\
\hline \multirow[t]{3}{*}{1} & $15 / 06 / 2016$ & 57,76 & 2,5 & 36,65 & 3,48 \\
\hline & & 75,83 & 6,863 & - & - \\
\hline & & 91,59 & 2,5 & - & - \\
\hline 2 & 15/07/2016 & 74,58 & 9,536 & 41,66 & 4,96 \\
\hline \multirow[t]{2}{*}{3} & 01/08/2016 & 44,07 & 2,5 & 29,78 & 2,5 \\
\hline & & 70,75 & 7,845 & 44,84 & 5,09 \\
\hline \multirow[t]{2}{*}{4} & $15 / 08 / 2016$ & 60,99 & 3,075 & 41,36 & 5,38 \\
\hline & & 72,67 & 7,367 & - & - \\
\hline \multirow[t]{2}{*}{5} & $15 / 09 / 2016$ & 66,19 & 4,419 & 36,28 & 6,34 \\
\hline & & 83,00 & 2,5 & 44,61 & 2,50 \\
\hline
\end{tabular}




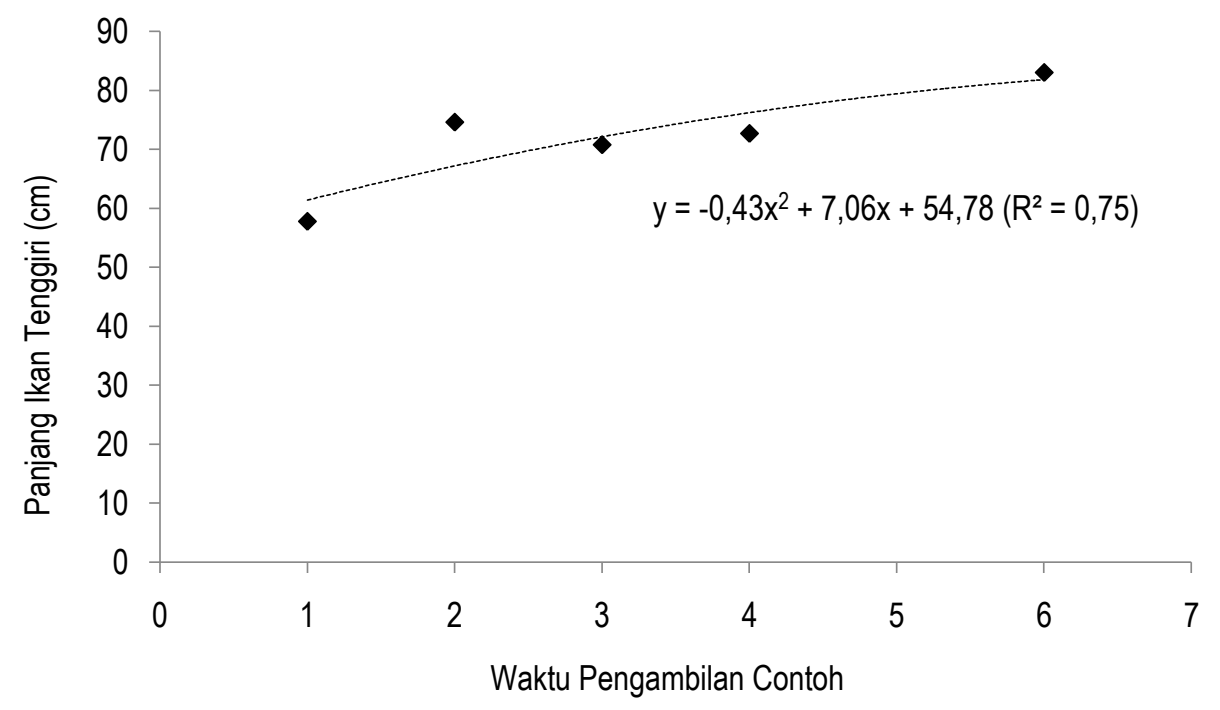

Gambar 3. Tren ukuran panjang ikan tenggiri per waktu pengambilan data

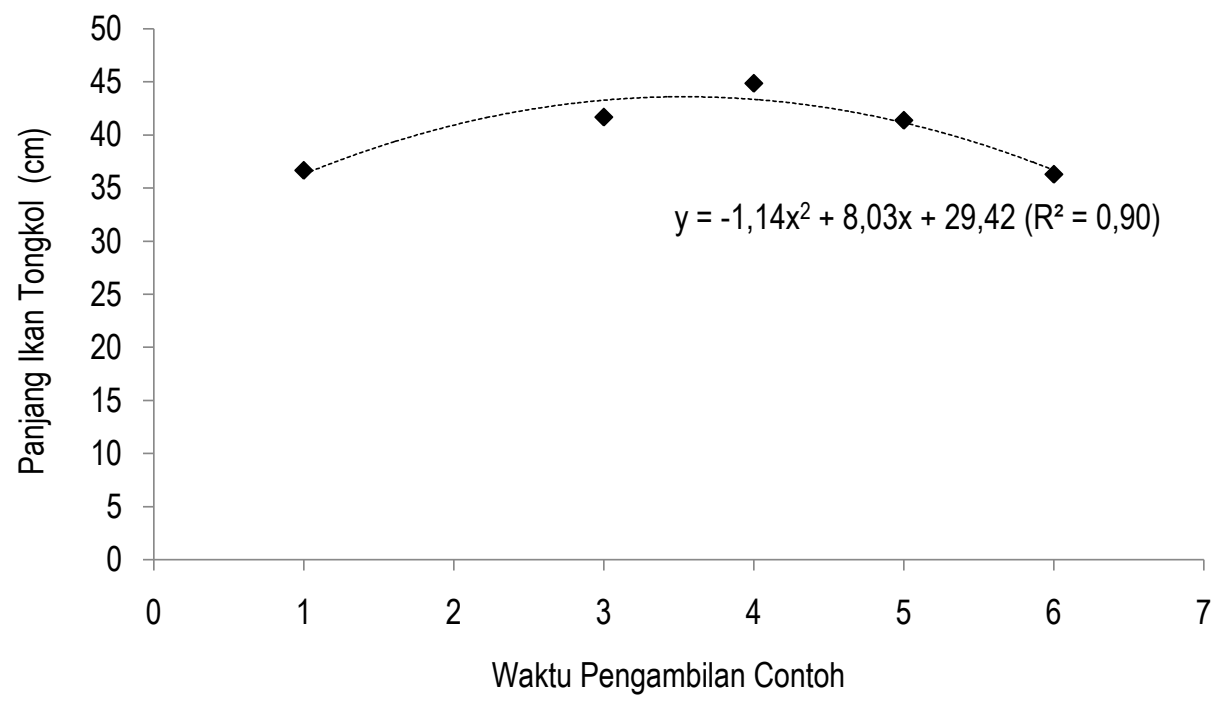

Gambar 4. Tren ukuran panjang ikan tongkol per waktu pengambilan data

Berdasarkan Gambar 3, tren ukuran ikan tenggiri selama lima kali pengambilan contoh cenderung meningkat. Pendugaan kelompok ukuran didasarkan pada sebaran kelas frekuensi panjang ikan. Pertumbuhan yang terjadi pada ikan digambarkan dengan adanya pergeseran modus ukuran panjang ikan ke arah kanan (Octoriani, Fahrudin, dan Boer, 2015). Grafik sebaran frekuensi panjang ikan tenggiri disajikan pada Gambar 5. Pergeseran modus kelompok ukuran ikan terlihat dari sampling 1-2, yaitu terjadi pertumbuhan modus ke arah kanan, dari $72,5 \mathrm{~cm}$ ke $77,5 \mathrm{~cm}$. Kemudian muncul modus baru di sampling 3-5 dari ukuran $42,5 \mathrm{~cm}$ sampai $82,5 \mathrm{~cm}$. 
Tren ukuran ikan tongkol selama 5 kali pengambilan contoh cenderung menurun (Gambar 4). Pertumbuhan ikan tongkol digambarkan dengan adanya pergeseran modus ukuran panjang ikan ke arah kanan (Gambar 6), terlihat dari sampling 1-3, dari ukuran ikan $32,5 \mathrm{~cm} ; 27,5 \mathrm{~cm}$; dan 42,5 $\mathrm{cm}$.
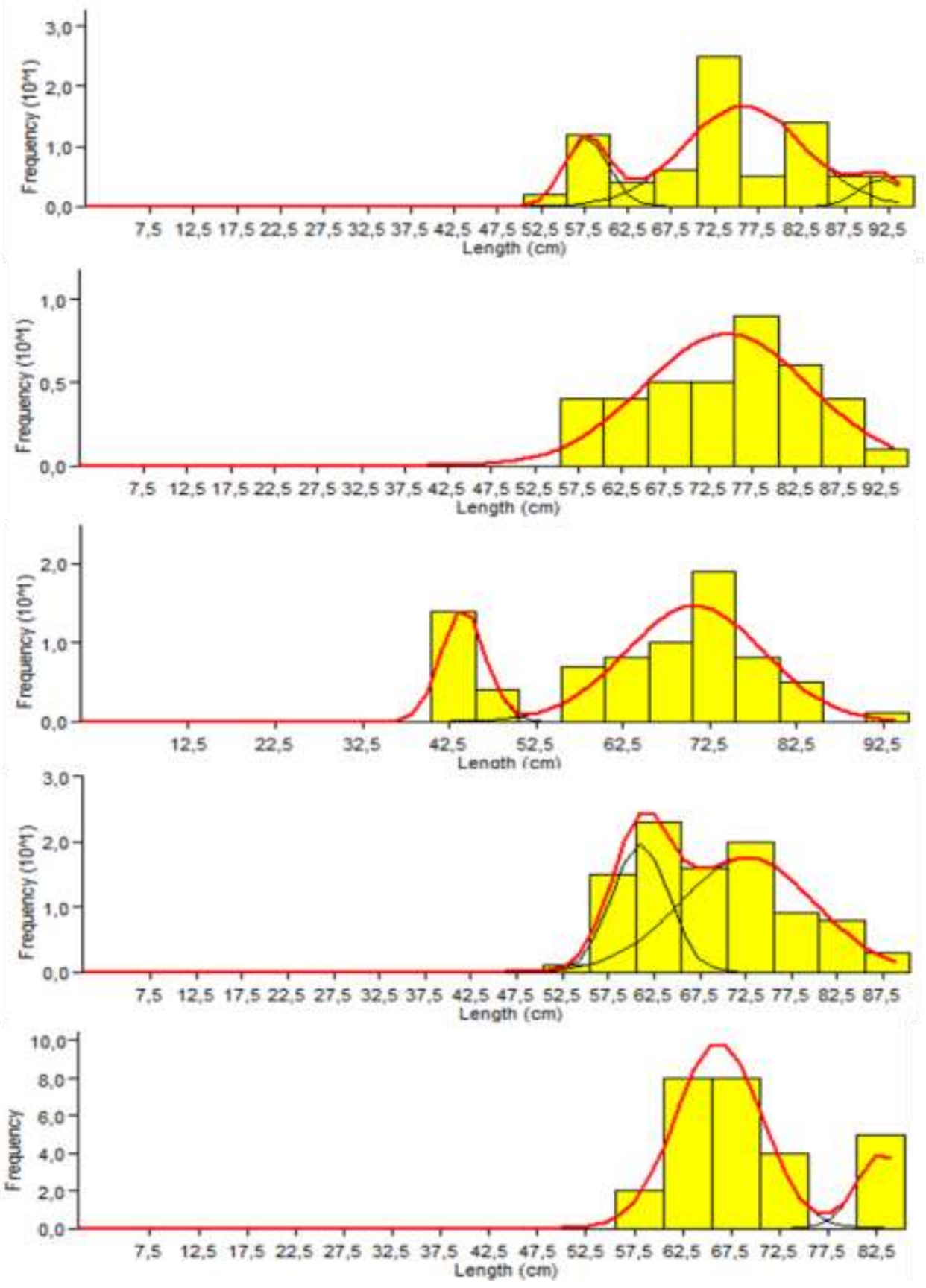

Gambar 5. Sebaran frekuensi panjang ikan tenggiri 

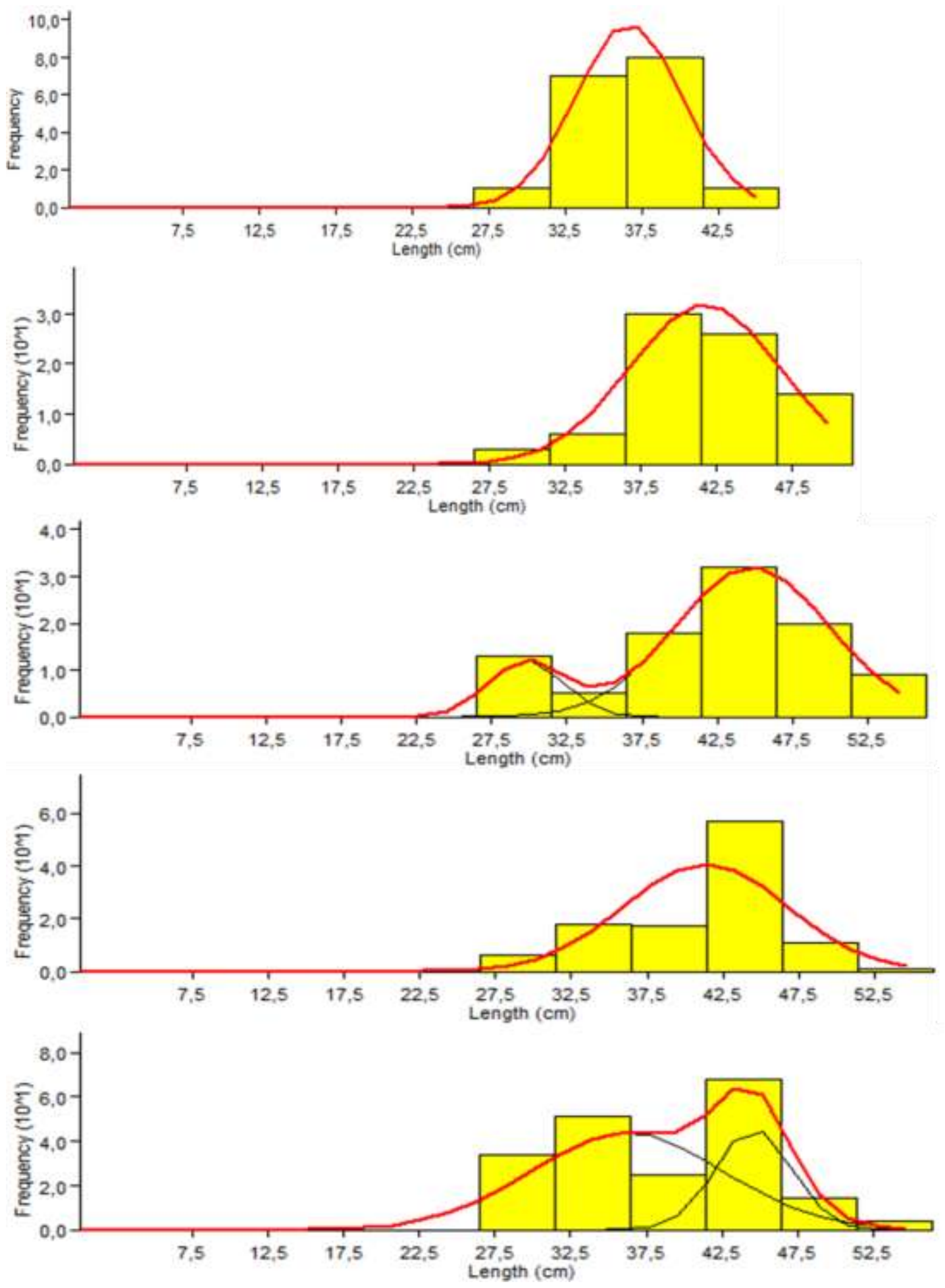

Gambar 6. Sebaran frekuensi panjang ikan tongkol 


\section{Pertumbuhan Ikan}

Berdasarkan pengelompokan ukuran dan pendugaan cohort ikan dapat diestimasi parameter pertumbuhan ikan tenggiri. Parameter pertumbuhan meliputi nilai koefisien pertumbuhan $(K)$, panjang asimptotik tubuh ikan $\left(\mathrm{L}_{\infty}\right)$, dan umur teoretik ikan pada saat panjang ikan nol $\left(\mathrm{t}_{0}\right)$ yang dianalisis dengan menggunakan Model Von Bertalanffy. Menurut Sparre dan Venema (1999) kajian pertumbuhan merupakan ukuran tubuh sebagai fungsi dari umur.

Ikan tenggiri merupakan ikan dengan umur yang panjang dengan Kyang relatif kecil sehingga lifespan-nya cukup lama yaitu 6,39 tahun (Tabel 3). Kurva pertumbuhan Von Bertalanffy ikan tenggiri berdasarkan ukuran ikan hasil sampling disajikan pada Gambar 7.

Tabel 3. Pendugaan Parameter Pertumbuhan Ikan Tenggiri.

\begin{tabular}{lr}
\hline \multicolumn{1}{c}{ Parameter pertumbuhan } & Nilai \\
\hline Panjang asimptotik $\left(\mathrm{L}_{\infty}\right)$ & $97,65 \mathrm{~cm}$ \\
Koefisien pertumbuhan $(\mathrm{K})$ & $0,45 /$ tahun \\
Umur ikan pada saat 0 tahun $\left(\mathrm{t}_{0}\right)$ & $-0,26$ tahun \\
Lifespan (tahun) & 6,39 tahun \\
\hline
\end{tabular}

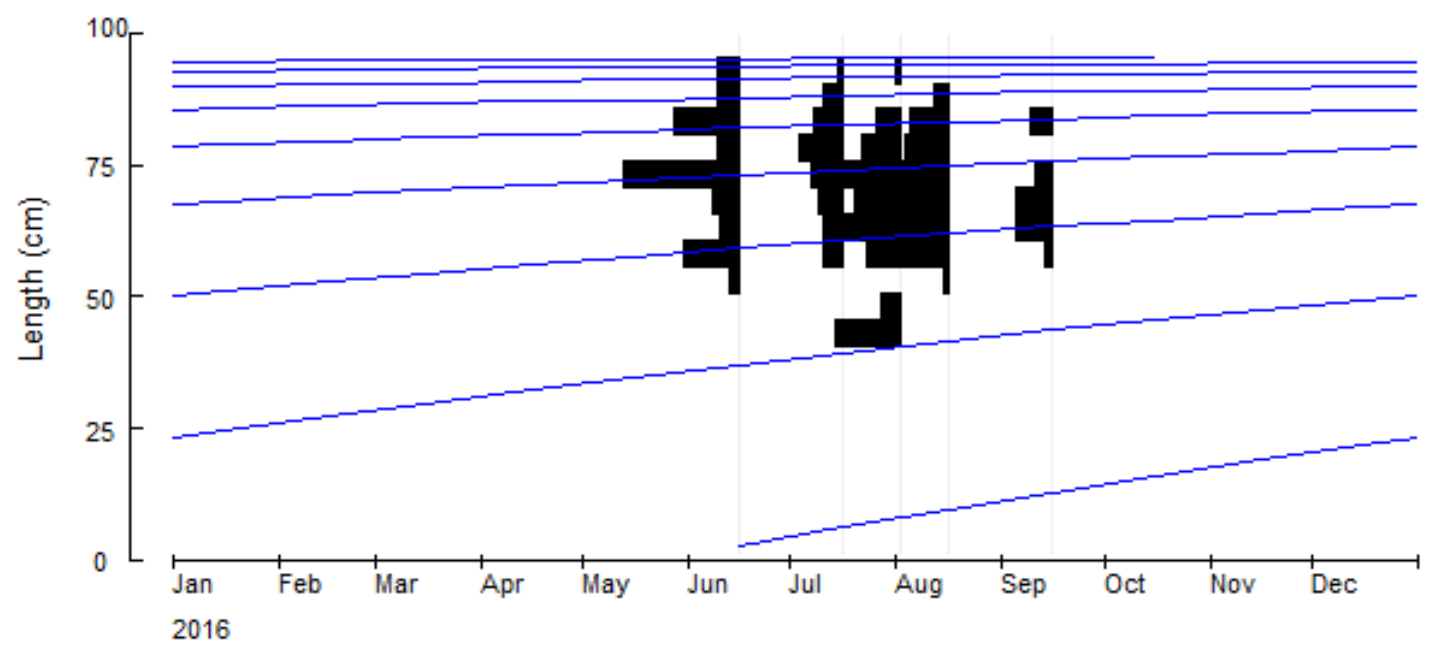

Gambar 7. Kurva pertumbuhan Von Bertalanffy untuk ikan tenggiri

Lifespan ikan tenggiri yang disajikan pada Tabel 3 tidak jauh berbeda dengan hasil penelitian Niamaimandi et al. (2015) bahwa umur maksimum yang dimiliki oleh ikan tenggiri (Scomberomorus commerson) di Perairan Bushehr (Iran) adalah enam tahun. Mcllwain et al. (2005) menambahkan bahwa hasil penelitian di Perairan Sultanate, Oman menunjukkan bahwa S. Commerson betina mempunyai nilai $L_{\infty}=140,44 \mathrm{~cm}$, dan nilai $K=0,31$; sedangkan untuk $S$. Commerson jantan mempunyai nilai $L_{\infty}=118,80 \mathrm{~cm}$ dan nilai $K=0.60$. Jika dibandingkan dengan $L_{\infty} S$. Commerson yang dicapai di Karimunjawa, maka ukuran yang ditemukan di Oman lebih panjang, diduga karena perbedaan kondisi perairan.

Parameter pertumbuhan ikan tongkol disajikan pada Tabel 4. Ikan tongkol memiliki koefisien pertumbuhan (K) yang tinggi (1,10/tahun), dan panjang asimptotik $\left(\mathrm{L}_{\infty}\right) 56,70 \mathrm{~cm}$, serta lifespan-nya pendek 2,60 tahun. Kurva pertumbuhan Von Bertalanffy ikan tongkol disajikan dalam Gambar 8. 
Tabel 4. Pendugaan Parameter Pertumbuhan Ikan Tongkol.

\begin{tabular}{lc}
\hline \multicolumn{1}{c}{ Parameter pertumbuhan } & Nilai \\
\hline Panjang asimptotik $\left(\mathrm{L}_{\infty}\right)$ & $56,70 \mathrm{~cm}$ \\
Koefisien pertumbuhan $(\mathrm{K})$ & $1,10 /$ tahun \\
Umur ikan pada saat 0 tahun $\left(\mathrm{t}_{0}\right)$ & $-0,12$ tahun \\
Lifespan & 2,60 tahun \\
\hline
\end{tabular}

Nilai Lø ikan tongkol di Karimunjawa (Tabel 4) lebih kecil dibandingkan dengan hasil penelitian Taghavi, Hashemi, \& Kochanian. (2010), bahwa ikan tongkol (Euthynnus affinis) mempunyai $L_{\infty}=87,66 \mathrm{~cm} ; \mathrm{K}=0,51 /$ tahun di perairan pesisir Provinsi Hormozgan, Iran. Hasil penelitian Khan (2004) di perairan Maharashtra, India menjelaskan bahwa rentang ukuran panjang $E$. Affinis adalah $26-73 \mathrm{~cm}$, dan $\mathrm{L}_{\infty}=81,7 \mathrm{~cm}$ and $\mathrm{K}=0,79$. Hasil penelitian di perairan Laut Jawa oleh Chodrijah, Hidayat, \& Noegroho (2013) menunjukkan temuan yang hampir sama dengan Tabel 4, yaitu $E$. Affinismempunyai $\left(\mathrm{L}_{\infty}\right)=59,63 \mathrm{~cm}$, kecepatan pertumbuhan ikan tongkol $(K)=0,91$. Dibandingkan dengan hasil-hasil penelitian tersebut, panjang asimptotik ikan tongkol pada penelitian ini $(56,70 \mathrm{~cm})$ mengalami sedikit penurunan. Hal tersebut menunjukkan bahwa ikan tongkol mengalami kenaikan tekanan penangkapan, sehingga ukurannya mencapai $<56,70 \mathrm{~cm}$ saja. Salah satu indikator peningkatan tekanan penangkapan ikan adalah menurunnya panjang ikan yang tertangkap (Agustina, Boer, \& Fahrudin 2015; Yuliana, dkk., 2016).

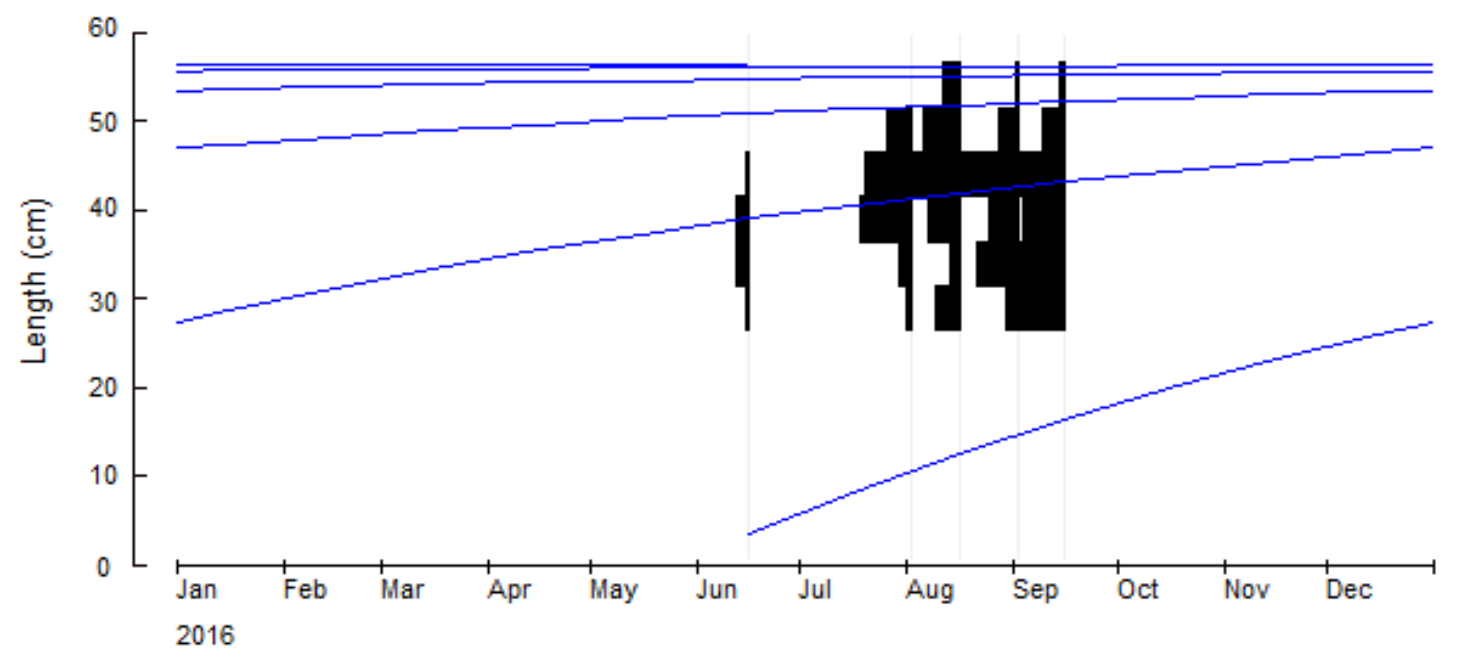

Gambar 8. Kurva pertumbuhan von bertalanffy untuk ikan tongkol

\section{Mortalitas dan Laju Eksploitasi}

Pendugaan mortalitas total (Z) ikan berdasarkan data panjang dengan metode lenght catch curve (Sparre \& Venema 1999) pada program FiSAT II. Pendugaan mortalitas dan tingkat eksploitasi berguna untuk mengestimasi biomassa ikan (Shephard et al., 2015). Mortalitas (Z) terdiri dari mortalitas akibat kematian alami (M) dan mortalitas akibat adanya penangkapan (F). Hasil penghitungan mortalitas dan laju eksploitasi disajikan dalam Tabel 5. 
Tabel 5. Mortalitas dan Laju Eksploitasi Ikan Tenggiri.

\begin{tabular}{lcc}
\hline Parameter mortalitas & Tenggiri & Tongkol \\
\hline Mortalitas total (Z)/(tahun) & 1,12 & 3,30 \\
Mortalitas alami (M) (/tahun) & 0,79 & 1,64 \\
Mortalitas penangkapan (F) (/tahun) & 0,33 & 1,66 \\
Laju eksploitasi (E) & 0,29 & 0,50 \\
\hline
\end{tabular}

Laju eksploitasi (E) ikan tenggiri masih dibawah pemanfaatan optimum $(0,5)$, sehingga kegiatan pemanfaatan masih dapat ditingkatkan sampai mencapai batas optimum (Pauly, 1987) dengan cara meningkatkan upaya penangkapan (Yuliana, dkk., 2016). Khusus untuk ikan tongkol, laju eksploitasinya sudah mencapai nilai 0,5 , sehingga aktivitas penangkapan ikan tongkol perlu hatihati, agar tidak mengarah ke penangkapan berlebih. Pengelolaan penangkapan ikan tongkol dapat dilakukan dengan pengaturan mata jaring, dan pengaturan ukuran panjang ikan minimum yang boleh diambil. Langkah-langkah pengelolaan tersebut dapat dituangkan di dalam kesepakatan desa, seperti yang sudah dilakukan pada jenis-jenis ikan kerapu (Yuliana, dkk., 2016). Kesepakatan desa tersebut mengatur secara adat dan diawasi oleh masyarakat sendiri tentang alat tangkap yang boleh digunakan, panjang minimum ikan yang boleh ditangkap, termasuk pelarangan penangkapan ikan ketika musim memijah.

\section{SIMPULAN}

Tren ukuran ikan tenggiri cenderung meningkat, dengan laju eksploitasi $(E)=0,29$ (under exploited), sehingga pemanfaatannya dapat ditingkatkan, namun ukuran ikan tongkol cenderung menurun, dengan laju eksploitasi $(E)=0,5$. Kondisi pemanfaatan ikan tongkol berada pada posisi mengkhawatirkan.

Perlu dilakukan pengelolaan terhadap penangkapan ikan tongkol agar tidak mengarah ke penangkapan berlebih, dengan mengatur alat tangkap nelayan. Pengelolaan tersebut dapat dituangkan dalam kesepakatan desa yang diawasi oleh masyarakat nelayan sendiri.

\section{REFERENSI}

Agustina, S., Boer, M., \& Fahrudin, A. (2015). Dinamika populasi sumberdaya ikan layur(Lepturacanthus savala) di Perairan Selat Sunda. Marine fisheries, 6(1);77-85.

Balai Taman Nasional Karimunjawa (BTNKJ). (2014). Statistik balai Taman Nasional Karimunjawa 2013. Semarang: BTNKJ.

Campbell SJ., Kartawijaya, T., Yulianto, I., Prasetia, R., \& Clifton, J. (2013). Co-management approaches and incentives improve management effectiveness in the Karimunjawa National Park, Indonesia. Marine policy, 41;72-79.

Charles, AT. (2001). Sustainable fishery systems. London: Balckwell Sciences.

Chodrijah, U., Hidayat, T., \& Noegroho, T. (2013). Estimasi parameter populasi ikan tongkol komo (Euthynnus affinis) di perairanLaut Jawa. BAWAL, 5(3);167-174.

Irnawati, R., Simbolon, D., Wiryawan, B., Murdiyanto, B., \& Nurani TW. (2011). Analisis komoditas unggulan perikanan tangkap di Taman Nasional Karimunjawa. Jurnal saintek perikanan, 7(1); $1-9$.

Khan, MZ. (2004). Age and growth, mortality and stock assessment of Euthynnus affinisfrom Maharashtra waters. Indian journal offFisheries, 51(2);209-213. 
Mcllwain, JL., Claereboudt, MR., Al-Oufi, HS., Zaki, S., \& Goddard, JS. (2005). Spatial variation in age and growth of the kingfish (Scomberomorus commerson) in the coastal waters of the Sultanate of Oman. Fisheries Research, 73(3);283-298.

Niamaimandi, N., Kaymaram, F., Hoolihan, JP., Mohammadi, GH., \& Fatemi, SMR. (2015). Population dynamics parameters of narrow-barred Spanish mackerel (Scomberomorus commerson) from commercial catch in the northern Persian Gulf. Global ecology and conservation, 4;666-672.

Octoriani, W., Fahrudin, A., Boer, M. (2015). Laju eksploitasi sumber daya ikan yang tertangkap pukat cincin di Selat Sunda. Marine fisheries, jurnal teknologi dan manajemen perikanan laut, 6(1);69-85.

Pauly, D. (1984). Fish population dynamics in tropical waters: a manual for use with programmable calculators. ICLARS Stud. Rev. 8;325.

Pauly, D. (1987). Review of the ELEFAN system for analysis of length-frequency data in fish and aquatic invertebrates. In length-based methods in fisheries research. iclarm conference proceedings 13. International Center for Living Aquatic Resources Management, Manila, Philippines, and Kuwait Institute for Scientific Research, Safat, Kuwait.

Pelabuhan Perikanan Pantai (PPP) Karimunjawa. (2014). Laporan tahunan pelabuhan perikanan pantai karimunjawa tahun 2014. Karimunjawa: PPP Karimunjawa.

Shephard, S., Reid, DG., Gerritsen, HD., \& Farnsworth, KD. (2015). Estimating biomass, fishing mortality, and "total allowable discards" for surveyed non-target fish. ICES journal of marine science, 72(2);458-466.

Sparre, P., \& Venema, SC. (1999). Introduksi pengkajian stok ikan tropis. Jakarta: Pusat Penelitian dan Pengembangan Perikanan, Badan Penelitian dan Pengembangan Pertanian.

Taghavi, MSA., Hashemi, SA., Kochanian, P. (2010). Population biology and assessment of kawakawa (Euthynnus affinis) in Coastal Waters of the Persian Gulf and Sea of Oman (Hormozgan Province). Iranian journal of fisheries sciences, 9(2);315-326.

Yuliana, E., Boer, M., Fahrudin, A., \& Muttaqin, E. (2016). Status stok ikan karang target di kawasan konservasi Taman Nasional Karimunjawa. Jurnal penelitian perikanan Indonesia, 22(1);9-16. 